\title{
RAÇÃO DE FARELO DE SOJA E DE SOJA INTEGRAL EXTRUSADA E DIFERENTES NÍVEIS DE SUBSTITUIÇÃO DO MILHO POR TITRICALE NA ALIMENTAÇÃO ANIMAL. I. DESEMPENHO NO CRESCIMENTO DE SUÍNOS
}

\section{LUIZ MÁRIO FEDALTO ${ }^{1}$; GIOVANA LAÍ́S RUVIARO TULESKI ${ }^{2}$; MARSON BRUCK WARPECHOSKI ${ }^{3}$; TATYANA BRAGA ${ }^{4}$}

\author{
${ }^{1,3}$ Departamento de Zootecnia do Setor de Ciências Agrárias; ${ }^{2}$ Acadêmica de Medicina Veterinária; \\ ${ }^{4}$ Acadêmica de Engenharia Agronômica da Universidade Federal do Paraná, Bolsistas do Programa \\ Institucional de Bolsas de Iniciação Científica - PIBIC-CNPq.
}

\begin{abstract}
In order to evaluate the use of triticale and extrused soy seeds in diets for growing swine, 60 crossbred animals had been random distributed in 2X5 fatorial arrangement (protein sources X maize replacement levels). The range of maize replacement it was from 0 to $100 \%$. There was no difference between the treatments $(\mathrm{P}>0,05)$ in the growth and finishing performance.
\end{abstract}

RESUMO - A fim de avaliar o uso de triticale e soja integral extrusada em dietas para suínos em crescimento, foram distribuídos ao acaso 60 animais mestiços em delineamento com arranjo fatorial 2X5 (fontes de proteína x nível de substituição do milho). A partir dos $71 \mathrm{~kg}$ de peso corporal médio, todos os animais receberam dieta a base de milho e farelo de soja até o abate. Não houve alteração significativa $(\mathrm{P}>0,05)$ dos tratamentos sobre o desempenho dos suínos durante a fase de crescimento, nem efeito residual na fase de terminação.

\section{Introdução}

Tendo em vista que grande parte dos custos na criação de suínos corresponde à alimentação, há necessidade de se pesquisar ingredientes alternativos para a formulação de rações. Destacam-se, nesse contexto, a soja extrusada e o triticale como fontes de proteína e energia, respectivamente.

O processo de extrusão, além de inativar os fatores antinutricionais existentes na soja crua, destrói a lipoxidase, aumenta a digestibilidade do óleo e desnatura proteínas antigênicas (HARPER, 1981). Dessa forma, a soja integral extrusada provavelmente pode substituir o farelo de soja sem comprometer o desempenho dos animais.

O triticale, um híbrido do trigo com o centeio, tem sido avaliado como fonte energética, substituindo o milho na formulação de rações. Segundo o NRC (1998), o triticale e o milho possuem teores médios de proteína bruta $(\mathrm{PB})$, lisina (L), energia digestível (ED) e metabolizável (EM) para suínos de, respectivamente: 12,50 e $8,3 \%$ (PB); 0,39 e 0,26 $\%$ (L); 3.320 e $3.525 \mathrm{kcal} / \mathrm{kg}$ (ED); 3.180 e $3.420 \mathrm{kcal} / \mathrm{kg}$ (EM).

Quanto ao uso de triticale na dieta de suínos em crescimento, FERREIRA et al. (1992), HALE e UTLEY (1985) e MYER et al. (1996) observaram que a substituição do milho por triticale não altera o consumo e o ganho de peso dos animai. Isso foi confirmado por FURLAN et al. (1997), que verificaram ainda uma melhora na conversão alimentar e redução no custo da ração por quilograma de peso vivo. Outros autores, entretanto, obtiveram resultados opostos, observando que a substituição de $100 \%$ do milho por triticale, em rações para suínos em crescimento, resulta em uma piora no ganho médio diário (ERICKSON et al., 1979; MYER et al., 1989; TYWONCZUK et al.,1996) e na conversão alimentar (COFFEY e GERRITS, 1988; MYER et al., 1989; TYWONCZUK et al.,1996)

O objetivo desse experimento foi avaliar os efeitos da utilização de soja integral extrusada e do triticale sobre o desempenho de suínos em crescimento. Além disso, foram verificados os efeitos dessas dietas sobre o desempenho na fase de terminação, quando os animais receberam ração tradicional à base de farelo de soja e milho.

\section{Materiais e Métodos}

Foram utilizados 60 leitões mestiços Landrace $\mathrm{x}$ Large White, num delineamento experimental em blocos casualizados, em esquema fatorial $2 \times 5$, sendo os fatores duas fontes proteína, farelo de soja (FS) e soja integral extrusada (SE) e cinco níveis de substituição do milho pelo triticale $(0,25,50,75$ e $100 \%$ ), com três repetições por tratamento e dois animais por unidade experimental.

Os animais iniciaram o experimento com pesos médios de $21,82 \mathrm{~kg}$. As trocas de ração ocorreram aos $71,20 \mathrm{~kg}$, quando todos os animais passaram a receber ração à base de farelo de soja e milho com $14 \%$ de proteína bruta e $3250 \mathrm{kcal} / \mathrm{EM} / \mathrm{kg}$. As rações de crescimento eram isolisínicas $(0,9 \%)$ e isoprotéicas $(16 \%)$, sem correção de seus valores energéticos. 
Foram controlados todos os fornecimentos, perdas $\mathrm{e}$ as respectivas sobras, obtendo-se $\mathrm{o}$ consumo diário de ração dos animais. Por ocasião do encerramento experimental foram aferidas as espessuras de toucinho no ponto P2, utilizando-se aparelho ultra-som da marca PIGSCAN-SFK.

Os resultados foram submetidos a análise de variância através do método dos quadrados mínimos para dados com números desiguais de subclasses, utilizando-se o programa SAEG - Sistema para Análises Estatísticas e Genéticas desenvolvido por EUCLIDES (1982). As médias dos tratamentos foram comparadas pelo teste de NEWMAN KEULS a 5\% e os níveis de substituição de milho pelo triticale foram desdobrados em contrastes ortogonais com o objetivo de ser estudada a regressão desta característica até o terceiro grau.

\section{Resultados e Discussão}

Os valores referentes às fontes de proteína, farelo de soja e soja extrusada, tais como peso médio, ganho de peso diário, consumo diário de ração e conversão alimentar não diferiram significativamente $(\mathrm{P}>0,05)$ durante as fase de crescimento, terminação, e crescimento-terminação, como demonstra o Tabela 1.

Da mesma forma, os níveis crescentes de substituição do milho por triticale não afetaram o desempenho dos animais (Tabela 1), coincidindo com os resultados obtidos por FERREIRA et al. (1992), HALE e UTLEY (1985) e MYER et al. (1996).

Tabela 1. Médias referentes ao peso $(\mathrm{kg})$, ganho de peso diário $(\mathrm{kg})$, consumo diário $(\mathrm{kg})$ e conversão alimentar dos animais em relação aos níveis crescentes de substituição do milho por triticale $(0,25,50,75$ e 100\%) e em relação à fonte protéica (FS=farelo de soja; $\mathrm{SE}=$ soja extrusada).

\begin{tabular}{|c|c|c|c|c|c|c|c|c|}
\hline \multirow[t]{2}{*}{ Características } & \multicolumn{5}{|c|}{ Níveis de substituição } & \multicolumn{2}{|c|}{ Fonte protéica } & \multirow{2}{*}{$\begin{array}{l}\text { Média } \\
\text { Geral }\end{array}$} \\
\hline & $0 \%$ & $25 \%$ & $50 \%$ & $75 \%$ & $100 \%$ & FS & SE & \\
\hline \multicolumn{9}{|l|}{ Fase crescimento } \\
\hline Peso inicial & 21,10 & 21,60 & 22,44 & 22,54 & 21,42 & 22,02 & 21,62 & 21,82 \\
\hline Peso final & 71,42 & 71,88 & 72,75 & 70,17 & 69,52 & 70,98 & 71,37 & 71,18 \\
\hline Ganho de peso diário & 0,833 & 0,841 & 0,848 & 0,791 & 0,833 & 0,834 & 0,823 & 0,829 \\
\hline Consumo diário & 2,18 & 2,21 & 2,25 & 2,18 & 2,28 & 2,25 & 2,18 & 2,22 \\
\hline Conversão alimentar & 2,61 & 2,64 & 2,66 & 2,76 & 2,75 & 2,71 & 2,66 & 2,69 \\
\hline \multicolumn{9}{|l|}{ Fase terminação } \\
\hline Peso de abate & 94,60 & 91,94 & 92,66 & 91,12 & 92,20 & 91,80 & 93,21 & 92,50 \\
\hline $\begin{array}{l}\text { Espessura de toucinho } \\
\text { abate }\end{array}$ & 29,53 & 29,03 & 26,81 & 27,89 & 30,83 & 29,05 & 28,58 & 28,82 \\
\hline Ganho de peso diário & 0.998 & 0.925 & 0.994 & 0.970 & 1.070 & 0,940 & 1,042 & 0,991 \\
\hline Consumo diário & 2,72 & 2,84 & 2,87 & 2,82 & 2,96 & 2,88 & 2,81 & 2,84 \\
\hline Conversão alimentar & 2,78 & 3,12 & 2,92 & 3,00 & 2,80 & 3,14 & 2,71 & 2,92 \\
\hline \multicolumn{9}{|c|}{ Fase crescimento-terminação } \\
\hline Ganho de peso diário & 0,881 & 0,855 & 0,870 & 0,830 & 0,888 & 0,855 & 0,875 & 0,865 \\
\hline Consumo diário & 2,30 & 2,36 & 2,38 & 2,34 & 2,44 & 2,41 & 2,32 & 2,36 \\
\hline Conversão alimentar & 2,63 & 2,76 & 2,72 & 2,84 & 2,74 & 2,82 & 2,66 & 2,74 \\
\hline
\end{tabular}

Durante a fase de terminação, quando todos os animais receberam a mesma ração à base milho e farelo de soja, os desempenhos não foram afetados pela dieta da fase de crescimento, apresentando ganhos de peso e conversões alimentares semelhantes (Tabela 1).

Assim, uma vez que não prejudica o desempenho dos animais em crescimento, o triticale pode ser uma alternativa em períodos de entressafra do milho, diminuindo o custo com a ração.

Em relação à fonte de proteína, a soja integral extrusada mostrou-se tão efetiva quanto o farelo de soja, sendo o seu uso indicado em função do custo e disponibilidade de cada ingrediente: farelo de soja, óleo e/ou soja integral extrusada.

\section{REFERÊNCIAS BIBLIOGRÁFICAS}

COFFEY, M.T.; GERRITS, W.J. Digestibility and feeding value of B858 triticale for swine. Journal of Animal Science, 66(11):2728-2735, 1988.

ERICKSON, J.P; MILLER, E.R.; ELLIOTT, F.C.; KU, P.K.; ULREY, D.E. Nutritional evaluation of triticale in swine starter and grower diets. J. Anim. Sci. Champaign, 48(3):547-553, 1979.

EUCLIDES, R. F. SAEG - Sistema de Análises Estatísticas e Genéticas. Viçosa. U.F.V., Central de Processamentos de Dados, 68p. 1982.

FERREIRA, A.S.; LIMA, G.J.M.M.; ZANOTTO, D.L.; BASSI, L.J. Triticale como alimento alternativo para suínos em crescimento e terminação. Rev. Soc. Bras. Zoot., Viçosa, 21(2):300-308, 1992. 
FURLAN, A. C.; MIKAMI, F.; MOREIRA, I.; SCAPINELLO, C.; MURAKAMI, E. A. Utilização do triticale (triticale turgidosecale) na alimentação de suínos em crescimento. In: REUNIÃO DA SBZ (34 : 1997 : Juiz de Fora). Anais. Juiz de Fora : SBZ, p.115-117, 1997.

HALE, O.M.; UTLEY, P.R. Value of Beagle 82 triticale as substitute for corn and soybean meal in the diet of pigs. J. Anim. Sci., Champaign, 60(5):1272-1279, 1985.

HARPER, J.M. Extrusion processing of food. Food Tecnology., 32(7):676-682, 1978.

MYER, R.O.; BARNETT, R.D.; CORNELL, J.A.; COMBS, G.E. Nutritive value of diets containing triticale and varying mixtures of trtiticale and maize for growing - finishing swine. Animal Feed Science and Technology, Amsterdam, 22(3):217$225,1989$.
MYER, R.O.; BRENDEMUHL, J.H.; BARNETT, R.D. Crystalline lysine and threonine supplementation of soft red winter wheat or triticale, low-protein diets for growing-finishing swine. J. Anim. Sci., Chanpaign, 74(3):577-583, 1996.

NATIONAL RESEARCH COUNCIL. Washington. Nutrients requirements of swine. 10. ed. Washington: National Academy Press, 1998, 189 p.

TYWONCZUK, J.; LIPINSK, K.; LEWICKI, C.; RAPCZYNSKA, I.; GOSCHORSKI, B. The use of different content of Grado tritical in complete mixtures for growing pigs. Acta Academiae Agriculturae ac Technicae Olstenensis Zootechnica. Olsztun, n. 42, p. 77-86, 1994. Nutrition Abstracts \& Reviews, Wallingford, 66(3):189, março, 1996. Ref. 1283. Resumo. 